\title{
PENGEMBANGAN PERANGKAT LUNAK DISTRIBUSI GNU/LINUX DENGAN FITUR KHAS GORONTALO
}

\author{
Walid Umar \\ SMK Negeri 4 Gorontalo \\ Email: walidumar@gmail.com
}

\begin{abstract}
ABSTRAK
GNU / Linux merupakan sebuah basis sistem operasi yang dikembangkan dengan lisensi bebas (Open Source), sehingga memungkinkan banyak pengguna untuk mengembangkan kembali Sistem Operasi berbasis GNU/Linux sesuai dengan kebutuhan dari masing-masing pengguna. Penelitian ini dilakukan untuk mengembangkan sebuah sistem operasi berbasiskan GNU/Linux dengan fitur edukatif dan memiliki layanan pengenalan tentang Gorontalo, yang meliputi pengenalan Sejarah, Budaya, Bahasa, Potensi Wisata, dan Kondisi Geografis Provinsi Gorontalo. Metode penelitian yang digunakan adalah Metode Research \& Development $(R \& D)$ yang meliputi Penelitian, Perencanaan, Pengembangan, Pengujian Awal, Revisi Produk, Uji coba operasional, Revisi Produk Operasional, Ujicoba Produk, Pengujian Produk Akhir, Implementasi dan Penyebaran. Peneliti melakukan tiga kali pengembangan dan perbaikan terhadap sistem operasi yang dikembangkan berdasarkan pada revisi yang diberikan oleh responden yang berlatar belakang sebagai pelajar dan pengajar. Penelitian ini telah menghasilkan sebuah produk Sistem Operasi berbasiskan GNU/Linux yang diberi nama "Saronde OS". Saronde OS memiliki kelebihan pada pengembangan kernel GNU/Linux yang telah dikembangkan sehingga memiliki kelebihan dari sisi performa sehingga lebih hemat sumber daya memory dan battery. Selain pengembangan performa peneliti mengembangkan fitur edukatif dan layanan pengenalan budaya dan bahasa Gorontalo.
\end{abstract}

Kata kunci: GNU/linux, distribusi linux, sistem operasi, gorontalo, open source, saronde OS

\begin{abstract}
GNU / Linux is a license-free (Open Source) basic operating system that can be developed, allowing many users to redevelop GNU / Linux-based Operating System suitable to the needs of each end user. The study aimed to develop a GNU / Linux-based operating system with educational features and includes the introduction of Gorontalo Province, which includes history, culture, language, potential, and geographic conditions. The method used Research \& Development $(R \& D)$ which includes research, planning, development, pre-test, product revision, operational trials, operational products revised, product tests, Product final test, and deployment implementation. Researchers conducted three times on development and improvement toward the operating system that was developed based on the revision given by the respondents with have a background as student and teacher. The study has resulted in a GNU / Linuxbased operating system product, named "Saronde OS". Saronde OS kernel has advantages in developing GNU / Linux that have been developed that has advantage in terms of performance, so that more efficient in memory and battery resources. In addition to performance development, researchers develop educational features and services in the introduction to culture and Gorontalo language.
\end{abstract}

Keywords: GNU/linux, linux distribution, operating systems, gorontalo, open source, saronde OS 1. PENGANTAR

Berdasarkan pada perkembangan Internet yang pesat, pengguna tentu banyak memperoleh kemudahan, untuk mengaksesan data dan informasi dengan cepat, mudah dan efisien. Akan tetapi hal ini tentu berdampak negatif, dengan adanya kecepatan akses data dan informasi sehingga dengan bebasnya pengguna melakukan berbagai aktivitas unduh \& unggah produk perangkat lunak / hasil karya cipta yang memiliki lisensi (copyright) secara bebas. sehingga hal tersebut secara langsung melanggar HAKI (Hak Atas Kekayaan Intelektual) yang telah diatur dalam Undang-Undang.

Berdasarkan pada hal tersebut maka perlu dikembangkan sebuah sistem operasi berbasis GNU/Linux yang bernama "SarondeOS", dimana memungkinkan pengguna untuk menggunakan, mengembangkan dan mendistribusikan kembali tanpa melanggar HAKI yang sehingga dapat mengurangi adanya pembajakan perangkat lunak komputer di Kota Gorontalo. Hal-hal yang mempengaruhi adanya pengembangan sistem operasi Distribusi Linux ini, karena kurangnya minat dari pengguna terhadap 
Sistem Operasi berbasis Linux, hal tersebut disebabkan kurang bersahabatnya pengguna (user friendly) dalam menggunakan Linux, untuk itu maka perlu dikembangkan Distribusi Linux yang memiliki Layanan dan Fitur khas Gorontalo.

Berdasarkan data statistik yang dirilis oleh Wikimedia, Presentasi minat pengguna Sistem Operasi Linux pada Tahun 2012 sangat minim. Minimnya penggunaan Linux di Masyarakat sehingga diharapkan dengan adanya pengembangan Distribusi Linux ini dapat melahirkan Distribusi Linux yang memiliki Fitur dan Layanan yang menarik sehingga dapat dapat memberikan implikasi yang positif bagi minat pengguna yang khususnya adalah pelajar untuk dapat menggunakan sistem operasi berbasis Linux, dimana distribusi SarondeOS akan dikembangkan dengan fitur yang mudah, bersahabat dengan pengguna dan memiliki layanan khas daerah Gorontalo seperti pengenalan sejarah, ras, agama, tarian, makanan khas, suku \& budaya.

\section{TINJAUAN PUSTAKA}

\subsection{Sistem Operasi}

Sistem Operasi adalah sebuah perangkat lunak (software) yang berfungsi untuk mengalokasikan sumber daya untuk proses. Sistem Operasi adalah suatu program yang mengontrol eksekusi program aplikasi dan berfungsi sebagai antarmuka (interface) antara pengguna komputer dengan hardware komputer [1]. arsitektur dasar sebuah sistem komputer dapat ditunjukkan pada gambar 1 berikut :

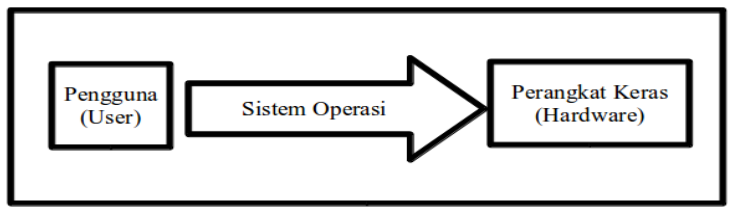

\subsection{Kernel}

Gambar 1. Alur Kerja Sistem Operasi [1]

Kernel adalah sebuah perangkat lunak yang didesain untuk mengalokasikan memory untuk proses yang dijalankan oleh user. Kernel merupakan jantung dari sistem operasi. Semua proses input dan output yang berlangsung selama komputer berjalan diatur oleh kernel seperti pembacaan dan penulisan terhadap disk, manajemen memory dan penjadwalan program aplikasi [2]. Perangkat lunak yang dikembangkan secara bebas dan terbuka (open source) memuat beberapa kriteria diantaranya [3] :

1. Bebas di distribusikan

2. Kode sumber yang terbuka

3. Dapat dikembangkan secara bersama-sama

4. Integritas pengembang awal perangkat lunak sumber terbuka

5. Tidak ada diskriminasi dari orang atau kelompok

6. Tidak ada diskriminasi berdasarkan lokasi / daerah / negara

7. Bebas di distribusikan dan dikembangkan kembali.

8. Lisensi tidak menspesifikasikan produk perangkat lunak

9. Tidak membatasi perangkat lunak lain.

10. Diharus menggunakan teknologi yang netral

Open Source Software merupakan sebuah pengembangan perangkat lunak dengan sumber yang dibuat terbuka agar dapat dipelajari dan dikembangkan kembali oleh pengembang lain. Open Source Software didefinisikan sebagai perangkat lunak yang dikembangkan secara gotong-royong tanpa koordinasi resmi, menggunakan kode program (source code) yang tersedia secara bebas, serta didistribusikan melalui media internet.

\subsection{General Public License}

Perangkat lunak yang menggunakan lisensi umum (General Public License) diwajibkan untuk mengacu ke empat prinsip dasar berikut [4] :

1. Kebebasan menjalankan program untuk tujuan apapun.

2. Kebebasan untuk mempelajari dan mengubah perangkat lunak.

3. Kebebasan untuk mendistribusi software secara bebas tanpa ada diskriminasi atas suku, ras, agama, dan budaya 
4. Kebebasan untuk mengembangkan dan merilis ke publik, sehingga dapat digunakan oleh masyarakat.

Lisensi GPL memberikan hak kepada orang lain untuk menggunakan sebuah ciptaan asalkan modifikasi atau produk dari ciptaan tersebut memiliki lisensi yang sama.

\subsection{GNU/LINUX}

$G N U$ adalah sebuah sistem operasi yang sepenuhnya terdiri dari perangkat lunak bebas, merupakan akronim untuk GNU's Not Unix (GNU Bukanlah Unix) [4]. Proyek ini memperkenalkan konsep copyleft yang pada dasarnya mengadopsi prinsip copyright, namun prinsip tersebut digunakan untuk menjamin kebebasan berkreasi. Jaminan tersebut berbentuk pelampiran kode sumber (source code), serta pernyataan bahwa perangkat lunak tersebut boleh dimodifikasi asalkan tetap mengikuti prinsip copyleft.

\section{CARA PENELITIAN}

Metode penelitian yang digunakan dalam penelitian distribusi Saronde OS adalah metode Research \& Development. Research \& Development adalah suatu proses atau langkah-langkah untuk mengembangkan suatu produk baru atau menyempurnakan produk yang telah ada sebelumnya [5]. Research \& Development memiliki 10 Tahapan penelitian yang terdiri dari 3 kali pengembangan produk setelah melakukan beberapa kali Pengujian Operasional terhadap produk yang akan dikembangkan. Adapun langkah-langkah penelitian yang telah dilakukan dapat dijelaskan pada beberapa tahapan berikut.

\subsection{Penelitian Dan Pengumpulan Data}

Pada tahapan ini peneliti melakukan pengumpulan data menggunakan teknik pengumpulan menggunakan kuisioner dan teknik wawancara pada pelajar dan pengajar yang menjadi objek penelitian.

\subsection{Perencanaan}

Setelah didapatkan data berupa fitur dan layanan yang dibutuhkan oleh pengguna. Selanjutnya berdasarkan data yang diperoleh maka akan direncanakan fitur dan layanan yang akan dikembangkan pada produk sistem operasi sesuai dengan kebutuhan pengguna.

\subsection{Pengembangan Produk Awal}

Setelah melalui proses perencanaan, pada tahapan ini peneliti akan melakukan pengembangan awal pada produk Distribusi SarondeOS yang meliputi pengembangan kernel, konten edukatif, dan layanan tentang Gorontalo.

\subsection{Pengujian Awal}

Setelah produk dikembangkan selanjutnya akan dilakukan pengujian awal yang bersifat personal tentang ke efektifan dan kestabilan produk yang dikembangkan.

\subsection{Revisi Produk}

Berdasarkan pada pengujian awal yang telah dilakukan selanjutnya akan dilakukan revisi / perbaikan berdasarkan pada pengujian awal yang telah dilakukan yaitu terhadap ketidak efektifan dan kurang stabilnya produk

\subsection{Uji Coba Lapangan}

Setelah melakukan revisi dan perbaikan, pada tahapan ini akan dilakukan pengujian lapangan. Pengujian lapangan akan dilakukan oleh objek penelitian, yang memiliki latar belakang sebagai pelajar dan pengajar khususnya yang ada di Provinsi Gorontao. Aspek-aspek pengujian yaitu meliputi kenyamanan, kemudahan dan kestabilan produk.

\subsection{Revisi Produk Operasional}


Berdasarkan pada masukkan yang telah dilakukan maka akan mendapatkan koreksi yang meliputi kekurangan dari produk yang telah dikembangkan, pada tahapan ini akan kembali dilakukan revisi terhadap produk yang sulit digunakan dan dimengerti oleh pengguna yang meliputi tampilan antarmuka produk perangkat lunak.

\subsection{Uji Coba Lapangan}

Pada tahapan ini akan dilakukan pengujian kembali terhadap produk yang telah dikembangkan dan dipaketkan kedalam sebuah Distribusi Saronde OS, sehingga dapat digunakan oleh responden. Sehingga berdasarkan dari pengujian yang telah dilakukan dilapangan maka akan menghasilkan temuan dan masukkan tentang produk yang dikembangkan baik dari sisi operasional dan antarmuka produk sistem operasi Saronde OS.

\subsection{Pengujian Produk Akhir}

Pada tahapan ini akan kembali dilakukan pengujian akhir terhadap produk yang telah dilakukan perbaikan sebelumnya, sehingga pada tahapan ini akan menghasilkan produk yang dapat digunakan.

\subsection{Implementasi dan Penyebaran}

Pada tahapan ini akan dilakukan implementasi dan penyebaran produk yang telah selesai dikembangkan sehingga sudah dapat digunakan dan dimanfaatkan oleh pengguna untuk mempermudah pekerjaan.

\section{HASIL PENELITIAN DAN PEMBAHASAN}

Berdasarkan pada hasil penelitian dengan menggunakan metode penelitian dan pengembangan maka menghasilkan sebuah produk Sistem Operasi SarondeOS yang dibangun berbasiskan Linux dengan beberapa konten khas Gorontalo dan konten Edukasi,

\subsection{Pengembangan Kernel}

Pengembangan Kernel Linux, merupakan pengembangan yang dilakukan dengan tujuan agar Distro Linux SarondeOS yang telah dikembangkan dapat berjalan lebih stabil dan mendukung banyak perangkat keras (hardware) peripheral seperti : Hardware CDROM Eksternal, Device Bluetooth, Perangkat Mouse \& Keyboard Wireless, Modem USB, Printer untuk semua tipe (Canon, HP, EPSON, dan lain - lain).

Pengembangan kernel dilakukan dengan tujuan agar, pengembangan Distro Linux, dapat mendukung dan memfasilitasi banyak perangkat lunak peripheral yang sebelumnya belum didukung karena, belum terdapatnya modul driver dari hardware didalam sistem kernel sebelumnya. Untuk itu perlu dilakukannya melakukan pengekstrakkan terhadap kernel, setelah melalui proses ekstrak akan dilakukan penambahan paket modul-modul hardware, dan selanjutnya kernel akan dipaketkan (compile) bersama modul-modul hardware yang telah ditambahkan sebelumnya. Adapun alur pengembangan Kernel Linux akan ditunjukkan pada Gambar 2 berikut :

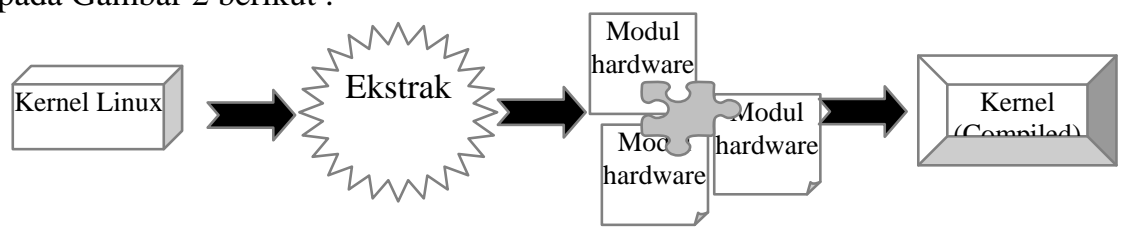

\section{Gambar 2. Alur Pengembangan Kernel Linux [1]}

Selain mengembangkan kernel untuk dukungan terhadap perangkat keras (hardware) peripheral, peneliti juga mengembangkan kernel linux agar memiliki fitur penghematan terhadap sumber daya (memory dan battery). hasil pengetesan kernel terhadap beberapa proses yang dijalankan, seperti yang ditunjukkan pada gambar 3 berikut : 


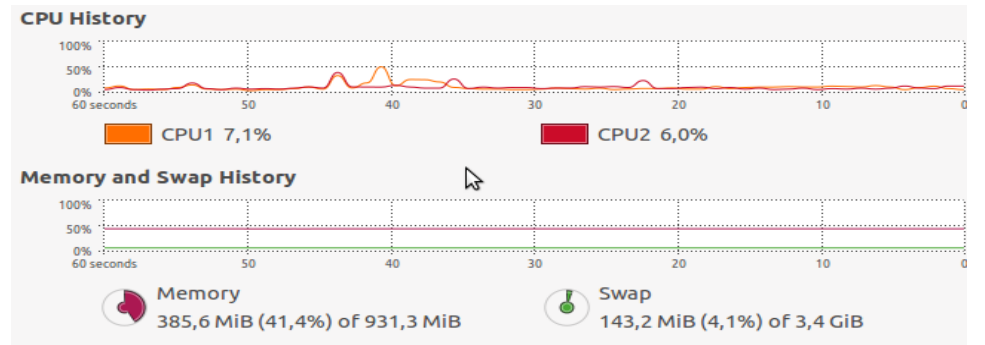

Gambar 3. Hasil pengetesan performa kernel pada perangkat keras (Hardware)

Versi kernel yang dimodifikasi dan dipaketkan kembali adalah kernel Linux 3.2.0-23 Generic Pae, seperti yang ditunjukkan pada Gambar 4 berikut :

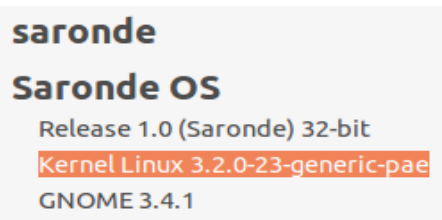

\section{Gambar 4. Versi kernel Linux yang dikembangkan}

Dengan adanya pengembangan Kernel Linux penggunaan sumber daya (battery) menjadi lebih stabil seperti yang ditunjukkan pada grafik gambar 5 berikut :

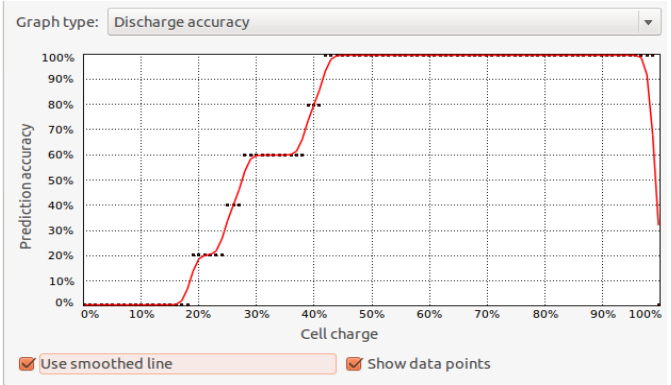

Gambar 5. Grafik penggunaan sumber daya power (battery)

Dengan adanya pengembangan kernel GNU/Linux yang dikembangkan sehingga memiliki beberapa kelebihan dibandingkan distribusi lainnya, kelebihan yang dimiliki oleh Saronde OS adalah dapat dilihat pada konsumsi penggunaan sumber daya untuk proses yang jauh lebih hemat, sehingga untuk menjalankan sebuah proses tidak memerlukan memory yang terlalu besar, untuk penggunaan sumber daya battery konsumsi penggunaan battery dapat lebih lama dari sebelumnya yaitu berbanding $5-10$ menit, karena SarondeOS menerapkan sistem safe resource, ketika perangkat laptop tidak terhubung dengan sumber daya listrik.

a) GORINDO, adalah sebuah pengembangan konten kamus Bahasa Indonesia-Gorontalo, diharapkan dengan adanya kamus ini dapat memperkenalkan budaya Gorontalo kepada generasi muda, khususnya pendatang yang belum dan ingin mengenal dan belajar bahasa Gorontalo.
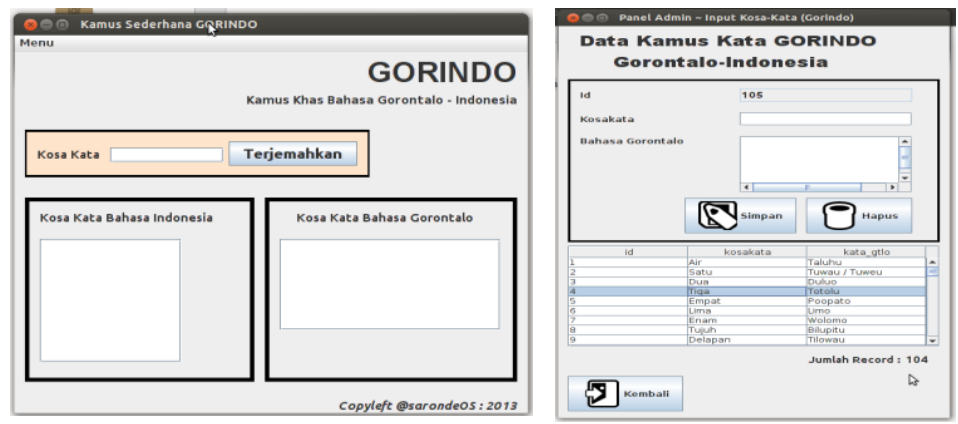

Gambar 6. Tampilan Kamus Gorindo (Gorontalo-Indonesia)

b) App-SarondeOS, merupakan sebuah aplikasi yang akan dikembangkan yang menawarkan fitur- 
fitur informasi tentang Provinsi Gorontalo yang meliputi : Sejarah Gorontalo, Suku \& Budaya Gorontalo, Pahlawan Gorontalo, Alat Musik Gorontalo, Makanan Khas Gorontalo, Tempat Wisata Provinsi Gorontalo, Tarian adat daerah Gorontalo, dan tentang pengenalan Sistem Operasi SarondeOS. Berikut adalah rancangan awal App-SarondeOS :
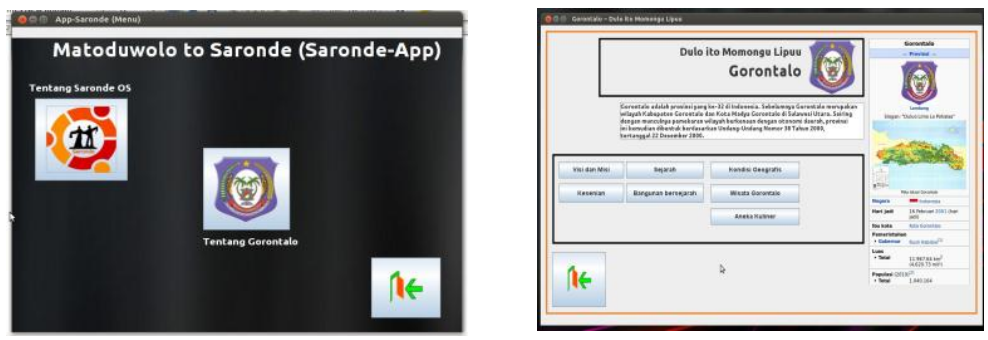

Gambar 7. Tampilan App-Saronde

c) Konten Edukasi merupakan konten yang disediakan dalam distribusi SarondeOS yang telah dikembangkan, sehingga dapat mempermudah pelajar yang nantinya akan menggunakan distribusi SarondeOS yang akan dikembangkan menjadi lebih mudah, dengan tersedianya perangkat lunak edukasi seperti yang ditunjukkan pada gambar 8

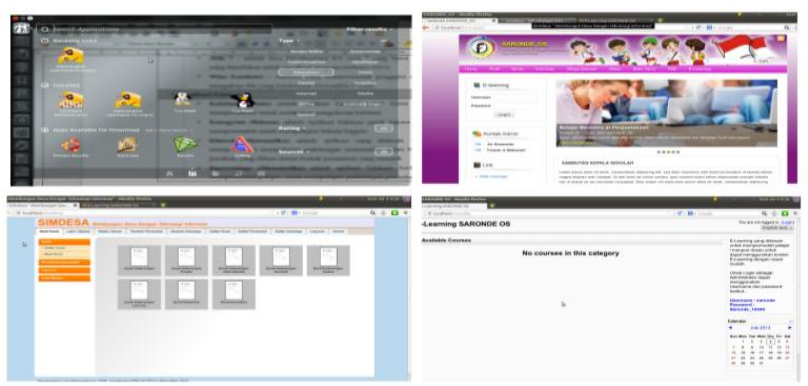

Gambar 8. Perangkat Lunak Edukasi

\section{KESIMPULAN}

Berdasarkan pada hasil penelitian yang telah dilakukan, maka dapat disimpulkan bahwa, dengan adanya pengembangan sebuah Distribusi Saronde OS dapat menjadi solusi kepada pengguna khususnya bagi pelajar Gorontalo untuk bermigrasi untuk menggunakan sistem operasi SarondeOS yang berlisensi GNU/GPL, sehingga berdasarkan hal tersebut dapat mengurangi tingkat pembajakan perangkat lunak yang ada di Gorontalo khususnya. Selain itu dengan adanya pengembangan konten-konten Khas Gorontalo dalam Distro "SarondeOS" yang telah dikembangkan, Dapat membantu mensosialisasikan tentang bahasa daerah Gorontalo (Bahasa lo hulondalo) dan beragam budaya, wisata, dan kuliner khas Gorontalo. Sehingga dapat memberikan implikasi yang positif bagi kemajuan Provinsi Gorontalo.

\section{DAFTAR PUSTAKA}

[1] Stallings, W. 2005. Operating System : Internal and Design Principles. Indeks Kelompok Gramedia Press.

[2] Santoso, H. 2005. Perancangan Sistem Operasi. Penerbit Andi Yogyakarta

[3] Opensource Initiative. 2005. “ The Open Source Definition ”. http://opensource.org. Diakses 30 Maret 2013 Jam 10.35 WITA

[4] Stallman. R. 2011. "Definition of GNU (Genuine Not Unix) http://www.gnu.org/gnu/linux-andgnu.id.html, diakses 1 April 2013.

[5] Juhaini. 2005. Research and Development : Metode Penelitian dan pengembangan http://file.upi.edu/Direktori/FIP/JUR._PEND.LUAR_BIASA/1960050519860 32JUAHINI/Presentasi_Research_and_Development.pdf Diakses 7 April 2013 